\title{
Efeito do melado de cana-de-açúcar no desenvolvimento in vitro de bananeira (Musa spp.) cv. Maçã ${ }^{1}$
}

\author{
Juliana Martins Ribeiro*2, Natoniel Franklin de Melo², Ângela Katiussia Nascimento dos Santos Coelho², \\ Márcio dos Santos Teixeira Pinto
}

\section{RESUMO}

Apesar de oferecer uma série de vantagens, quanto à qualidade do produto final, a técnica de cultivo in vitro de plantas ainda é considerada dispendiosa, por causa, dentre outros fatores, da utilização de reagentes com alto grau de pureza no preparo de meios nutritivos. Entre as alternativas que podem ser adotadas para a redução dos custos relacionados com a produção de mudas, apresenta potencial a substituição de produtos PA por aqueles de menor custo. Baseado nestas informações, o objetivo deste estudo foi avaliar o efeito do melado de cana-de-açúcar sobre o desenvolvimento in vitro de bananeira, cv. Maçã. Para tal propósito, plantas de bananeira foram inoculadas em meios nutritivos, formulados à base de melado de cana-de-açúcar, com quatro concentrações distintas (brix de 1,5; 3,0; 4,5 e 6,0), e os dados obtidos foram comparados com aqueles das plantas cultivadas em meio MS (controle), perfazendo um total de cinco tratamentos. Apesar de terem-se desenvolvido em todos os tratamentos testados, observou-se que, para as variáveis número médio de folhas e biomassa da matéria fresca, as plantas cultivadas no meio MS (controle) apresentaram valores superiores. Entretanto, para o número médio de raízes, não houve diferença estatística entre os tratamentos utilizados. O melado de cana-de-açúcar não favorece o desenvolvimento de plântulas de bananeira, mas pode ser utilizado para o enraizamento dessas plantas in vitro.

Palavras-chave: redução de custos, micropropagação, reagente comercial.

\section{ABSTRACT}

\section{Effect of sugarcane molasses on the in vitro development of banana (Musa spp.) cv. Maçã}

Despite offering a number of advantages as the quality of final product, the technique of in vitro cultivation of plants is still considered expensive due to, among other things, the use of reagents with high purity for the preparation of nutrient media. Among the alternatives that can be adopted to reduce the costs associated with the production of seedlings, the replacement of the PA product for those with lower has potential. Based on this information, the purpose of this study was to evaluate the effect of molasses of sugar cane on in vitro development of banana cv. Maçã. For this purpose, banana plants were inoculated in nutrient media made on the basis of sugarcane molasses, with four different concentrations (Brix of 1.5, 3.0, 4.5 and 6.0) and data were compared with those of plants grown on MS medium (control), in a total of five treatments. Despite plants have been developed in all treatments, it was observed that for the variables leaf number and fresh biomass, plants cultivated in MS medium (control) had higher performances. However, for the average number of roots, there was no statistical difference between treatments. The sugarcane molasses did not favor the development of banana plants, but can be used for in vitro rooting of these plants.

Key words: cost reduction, micropropagation, commercial reagent.

\footnotetext{
Recebido para publicação em 21/09/2011 e aprovado em 02/03/2012

${ }_{1}^{1}$ Trabalho financiado pela Embrapa Semiárido e FACEPE.

${ }^{2}$ Bióloga, Doutora. Embrapa Semiárido, Rodovia BR 428, Km 152, Caixa Postal 23, Zona Rural, 56302-970, Petrolina, Pernambuco, Brasil. juliana.ribeiro@cpatsa.embrapa.br (autora correspondente)

2 Biólogo, Doutor. Embrapa Semiárido, Rodovia BR 428, Km 152, Caixa Postal 23, Zona Rural, 56302-970, Petrolina, Pernambuco, Brasil. natoniel@cpatsa.embrapa.br ${ }^{3}$ Assistente de pesquisa. Laboratório de Biotecnologia Vegetal, Embrapa Semiárido, Rodovia BR 428, Km 152, Caixa Postal 23, Zona Rural, 56302-970, Petrolina, Pernambuco, Brasil. angela@cpatsa.embrapa.br

${ }^{4}$ Biólogo, Doutor. Laboratório de Biotecnologia Vegetal, Embrapa Semiárido, Rodovia BR 428, Km 152, Caixa Postal 23, Zona Rural, 56302-970, Petrolina, Pernambuco, Brasil. Bolsista DCR CNPq/ FACEPE. marciostp@yahoo.com.br
} 


\section{INTRODUÇÃO}

A banana (Musa spp.) é uma das frutas mais consumidas no mundo, sendo cultivada na maioria dos países tropicais, destacando-se, no Brasil, como um dos principais produtos agrícolas na preferência dos consumidores (Teixeira, 2000). Entretanto, o sistema de propagação convencional da bananeira é mais lento e apresenta menor rendimento quando comparado com a técnica de micropropagação (Pereira et al., 2005). Sendo assim, a micropropagação da bananeira pode ser considerada uma alternativa viável para a produção comercial de mudas, já tendo sido realizados vários trabalhos visando à otimização de protocolos para esta cultura (Diniz et al., 1996 a e b; Bernardi et al., 2004; Costa et al., 2008; Ramos et al., 2009; Camolesi et al., 2010; Madail, et al., 2011).

A utilização da micropropagação para a produção de mudas de bananeira aumenta de maneira considerável o número de plantas livres de pragas e doenças, como o Mal-do-Panamá (Fusarium oxysporium f. sp. cubense), Moko (Pseudomonas solanacearum), a Sigatoka-negra (Mycosphaerella fijiensis var. difformis), o nematoide (Radopholus similis) e a Broca-do-rizoma (Cosmopolites sordidus), dentro de um curto espaço de tempo (Sá \& Braga, 2002).

Além da obtenção de mudas livres de doenças e pragas, as mudas micropropagadas são produzidas, rapidamente, em espaço físico reduzido, são fáceis de serem transportadas, proporcionam uniformidade nos tratos culturais e na colheita, no primeiro ciclo da cultura, e são mais produtivas no primeiro ciclo em comparação com as convencionais (Pereira et al., 2005).

Além disso, plantas de bananeira micropropagadas crescem mais rapidamente nos primeiros estádios de desenvolvimento, em comparação com as mudas convencionais, apresentam maior precocidade, florescendo até quatro meses antes das plantas convencionais, e proporcionam colheitas superiores (Álvares \& Caldas, 2002).

Embora seja uma tecnologia que apresente uma série de vantagens, quanto ao produto final, a técnica de cultivo in vitro de plantas ainda é considerada dispendiosa, por causa, principalmente, da aquisição e manutenção de determinados equipamentos, bem como da utilização de reagentes com alto grau de pureza (PA), no preparo de meios nutritivos.

Características, consideradas importantes, para tornar uma biofábrica mais econômica seriam a substituição da técnica de autoclavagem por outra mais econômica (Teixeira et al., 2006; Teixeira et al., 2008; Ribeiro \& Teixeira, 2008 a e b; Ribeiro et al., 2008; Ribeiro et al., 2009; Ribeiro et al., 2011), o uso da luz solar na iluminação da sala de crescimento de plantas (Ponce et al., 2000) e a substituição de reagentes PA por aqueles de menor custo (Bernardi et al., 2004; Faria et al., 2006; Costa et al., 2007; Viaganó et al., 2007; Ribeiro \& Teixeira, 2008b). Kodym e Zapata (2001) afirmam que apenas com a utilização da luz natural e a substituição de alguns reagentes no meio de cultura por produtos de menor custo, pode haver uma redução no custo de produção, em até $90 \%$, em laboratório de produção de mudas.

A utilização de reagentes PA no preparo de meios nutritivos para o cultivo de plantas deve-se ao fato de conterem quantidades reduzidas de impurezas, minimizando possíveis influências negativas de outras substâncias químicas na reação das plantas cultivadas. Entretanto, grande parte dos componentes dos meios de cultura é disponibilizada comercialmente, apresentando a mesma concentração do nutriente e baixo custo de aquisição. Além disso, reagentes com alto grau de pureza são indispensáveis apenas para estudos de algum fenômeno específico in vitro. Para a produção comercial de plantas em laboratórios tal grau de pureza não é necessário (Prakash et al. 2004), desde que sejam adotadas técnicas eficientes de esterilização para a eliminação das impurezas.

O melado de cana-de-açúcar pode ser utilizado como fonte de vários nutrientes, entre eles, açúcar, vitaminas e íons metálicos inorgânicos necessários para indução de calos e para a formação de brotos (Prakash et al. 2004), já tendo sido utilizado com sucesso em experimentos de micropropagação (Dhamankar, 1992; Santana et al., 2009). Baseado nestas informações, o objetivo deste estudo foi avaliar o efeito de melado de cana-de-açúcar sobre o desenvolvimento in vitro de bananeira cv. Maçã.

\section{MATERIAL E MÉTODOS}

O material vegetal utilizado para a realização deste experimento foi proveniente de culturas estoque de bananeira, cv. Maçã, mantidas em sala de crescimento por 60 dias, sob fotoperíodo de 16 horas, temperatura variando entre 23 e $27^{\circ} \mathrm{C}$ e intensidade luminosa de $40 \mu \mathrm{mol} \mathrm{m}^{-2}$. Estas culturas foram iniciadas in vitro, a partir de meristemas de plantas cultivadas no campo.

O meio de cultura, utilizado para o cultivo das plantas in vitro, foi preparado de acordo com a formulação de sais inorgânicos de MS (Murashige \& Skoog, 1962) vitaminas White (White, 1943), 100 $\mathrm{mg} \mathrm{L}^{-1}$ de inositol, 6,5 g L${ }^{1}$ de agar, $30 \mathrm{~g} \mathrm{~L}^{-1}$ de sacarose, 2,5mg L L ${ }^{-1}$ de BAP, $\mathrm{pH}$ 5,9 e esterilizado por autoclavagem $\left(121^{\circ} \mathrm{C}\right.$, por 20 minutos).

No interior da capela de fluxo laminar, plantas com aproximadamente $1 \mathrm{~cm}$ foram retiradas dos frascos nos quais estavam sendo cultivadas e transferidas para placa de Petri. As brotações foram separadas e delas retiradas todas as folhas e raízes. Todos os procedimentos acima foram realizados em condições assépticas, com a utilização de vidrarias e utensílios esterilizados. 
Os explantes citados foram transferidos para tubos de ensaio de 25 x $150 \mathrm{~mm}$, contendo $20 \mathrm{~mL}$ dos seguintes tratamentos: T1) meio MS adicionado de 2,5 $\mathrm{mg} \mathrm{L}^{-1}$ de BAP e 6,5 $\mathrm{g} \mathrm{L}^{-1}$ de agar; T2) meio nutritivo à base de melado de cana-de-açúcar, diluído em água destilada até atingir brix de 1,5; T3) meio nutritivo à base de melado de cana-de-açúcar, diluído em água destilada até atingir brix de 3,0; T4) meio nutritivo à base de melado de cana-deaçúcar, diluído em água destilada até atingir brix de 4,5 e T5) meio nutritivo à base de melado de cana-de-açúcar, diluído em água destilada até atingir brix de 6,0. Aos tratamentos T2, T3, T4 e T5, foram adicionados 2,5 $\mathrm{mg} \mathrm{L}^{-1}$ de BAP, 6,5 $\mathrm{g} \mathrm{L}^{-1}$ de agar e 1,65 $\mathrm{g} \mathrm{L}^{-1}$ de nitrato de amônio.

O Brix foi medido em refratômetro, para que fosse realizada uma comparação com o meio MS, em relação ao seu percentual de solutos. Os valores de Brix testados foram baseados em concentrações de solutos, anteriormente utilizadas em ensaios para meio MS, principalmente ensaios de sacarose, que é o principal componente do melado de cana-de-açúcar. O meio MS apresentou comparativamente uma concentração de solutos de 3\%, relativa a um Brix de 3,0.

O nitrato de amônio foi adicionado a estes tratamentos em função de o melado possuir pouca quantidade de nitrogênio. $\mathrm{O}$ pH de todos os tratamentos foi aferido para 5,9 e os meios nutritivos foram esterilizados por autoclavagem $\left(121^{\circ} \mathrm{C}\right.$, por 20 minutos).

Após sessenta dias de cultivo, em sala de crescimento com as condições supracitadas, foram tomados dados do número médio de folhas e de raízes, bem como a biomassa da matéria fresca das culturas. Foi adotado o período de 60 dias para a análise das plantas, em função de este ter sido o tempo necessário para a obtenção de plantas completas de bananeira cv. Maçã.

O experimento foi conduzido em delineamento inteiramente casualizado, com cinco tratamentos, cinco repetições e a unidade experimental composta de quatro tubos de ensaio. Foi realizada a análise de variância e as médias foram comparadas pelo Teste de Tukey, a 5\% de probabilidade.

\section{RESULTADOS E DISCUSSÃO}

Decorrido um mês de cultivo nos tratamentos citados, foi observado o seu comportamento in vitro, especialmente em relação à contaminação, oxidação dos explantes e à formação de folhas e raízes. A Figura 1 mostra o desenvolvimento das plantas nos diferentes tratamentos adotados (Figura 1).

Não foram observadas contaminações de nenhuma natureza (fungos ou bactérias) nem a formação de raízes nas plantas cultivadas, em todos os tratamentos, no período de um mês. Entretanto, foi observado que as plantas cultivadas no tratamento cinco (T5) apresentavam-se, em sua maioria, oxidadas, e as cultivadas no tratamento um (controle) apresentavam-se visualmente mais desenvolvidas e com maiores números de folhas.

A oxidação dos explantes é um fenômeno que geralmente ocorre em função da liberação de compostos fenólicos pelos tecidos, em resposta aos ferimentos, altas concentrações de reguladores de crescimento no meio de cultura, ou pela oxidação de polifenóis e quininas (Ledo et al., 2002). O melado, por ser um produto da desidratação da cana-de-açúcar, possui em sua composição uma elevada concentração de compostos fenólicos (Olbrich, 2006; Takara, 2007), que podem ter sido responsáveis pelo elevado nível de oxidação dos explantes.

O meio nutritivo MS apresenta formulação de sais inorgânicos definida, contendo todos os nutrientes necessários e em concentrações ideais para o desenvolvimento in vitro de plantas de várias espécies, inclusive de bananeiras (Diniz et al., 1996 a e b; Bernardi et al., 2004; Costa et al., 2008; Ramos et al., 2009; Camolesi et al., 2010; Madail, et al., 2011), fator este que justificaria o melhor desenvolvimento visual, observado nas plantas cultivadas neste meio nutritivo, no período de um mês. O melado de cana-de-açúcar, entretanto, é composto, em sua maioria, por açúcares (62\%), sendo eles a sacarose (32\%), a glicose (14\%) e a frutose (16\%). Os demais componentes são: água (20\%), materiais nitrogenados e ácidos livres e ligados (10\%), bem como compostos inorgânicos (8\%), incluindo alguns macro e micronutrientes (Olbrich, 2006).

Couceiro et al. (2001), visando a estabelecer uma concentração ótima de sacarose para o crescimento de bananeiras cv. Maçã in vitro, observaram que a produção de matéria fresca é inversamente proporcional à concentração de sacarose, e que as plantas cultivadas em sacarose a $20 \mathrm{~g} \mathrm{~L}^{-1}$ apresentaram uma produção de matéria fresca quase três vezes superior ao observado com $80 \mathrm{~g} \mathrm{~L}^{-1}$. Embora exista o efeito inibitório de alta concentração do soluto sacarose sobre o desenvolvimento de explantes de banana, outros componentes inibidores presentes no melado podem ter influenciado o desenvolvimento dos explantes.

A Tabela 1 mostra os dados obtidos após a análise de variância do número médio de folhas, da biomassa da matéria fresca e do número médio de raízes, obtidos nos diferentes tratamentos testados. Verifica-se que houve diferenças estatísticas entre os tratamentos, tanto quanto ao número médio de folhas, como à biomassa da matéria fresca. No entanto, para número médio de raízes não houve diferenças estatísticas entre os diferentes tratamentos testados.

Conforme os resultados da Tabela 2, o número de folhas e a biomassa da matéria fresca foram maiores quando 


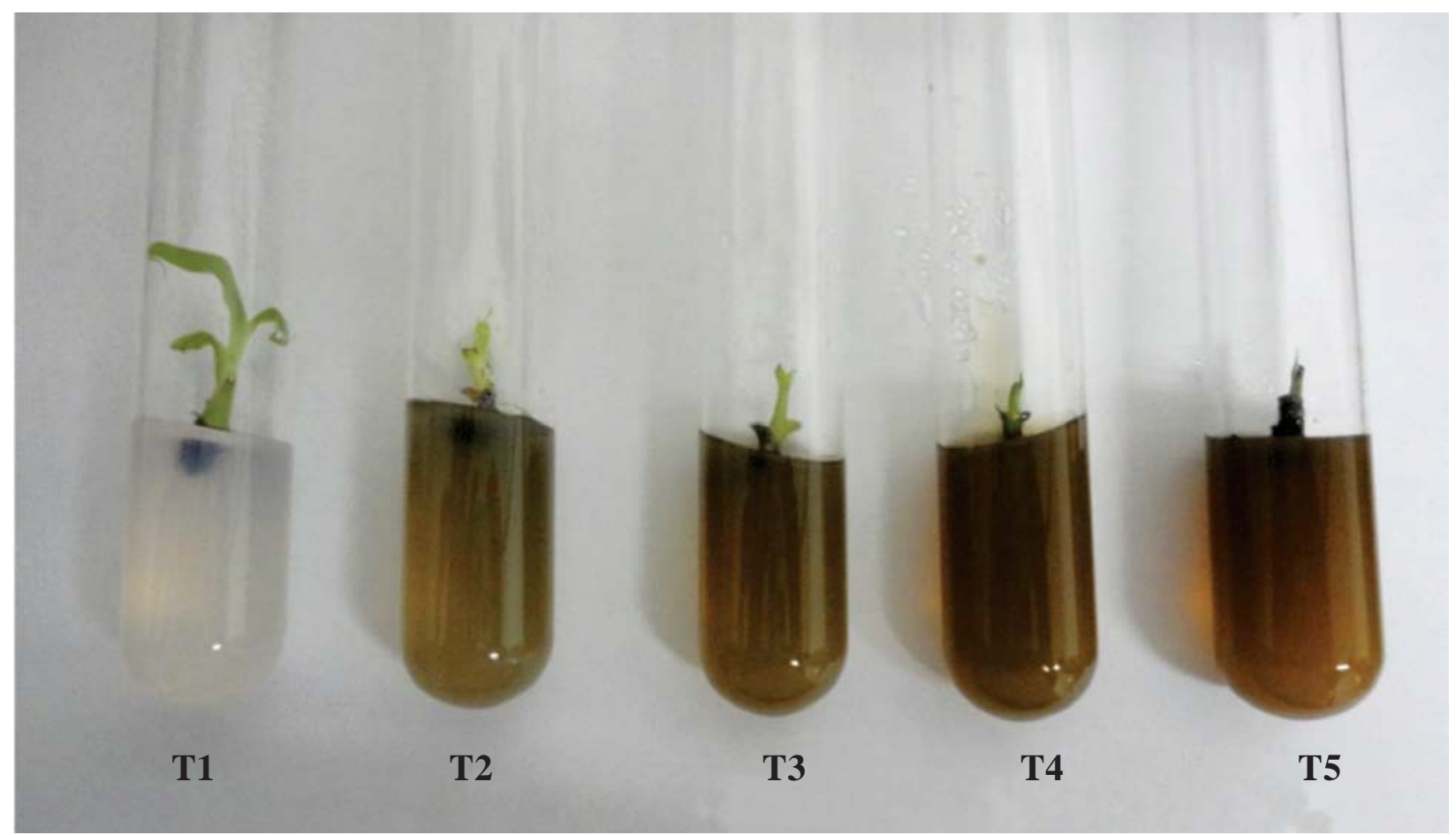

Figura 1. Desenvolvimento in vitro de plantas de bananeira nos diferentes tratamentos após um mês de cultivo. T1: meio MS (controle); T2: meio nutritivo à base de melado de cana-de-açúcar (brix 1,5); T3: meio nutritivo à base de melado de cana-de-açúcar (brix 3,0); T4: meio nutritivo à base de melado de cana-de-açúcar (brix 4,5) e T5: meio nutritivo à base de melado de cana-de-açúcar (brix 6,0).

usado o meio nutritivo com a formulação de sais inorgânicos de MS, quando comparados com os resultados dos meios nutritivos preparados à base de melado de canade-açúcar. Entretanto, para a variável número médio de raízes, não houve diferença estatística entre o tratamento controle e aqueles formulados com melado de cana-deaçúcar (Tabela 2).

O menor desenvolvimento das plantas, observado ao se utilizar um derivado da cana-de-açúcar como fonte de nutrientes, também pode estar relacionado com o fato de esses produtos apresentarem fatores inibitórios do crescimento (Buah et al., 2011). Os autores citados, trabalhando com caldo de cana, um outro derivado de cana-deaçúcar, observaram que uma concentração mais elevada de caldo no meio de cultura inibia o desenvolvimento de explantes de bananeira, sendo o fator limitante para o crescimento das plantas.
Observou-se que, na concentração de Brix de 1,5, a biomassa de matéria fresca correspondeu a menos da metade daquela do controle e permaneceu constante até o valor de Brix de 6,0. Além do desenvolvimento reduzido em todos os tratamentos, utilizando melado de cana-deaçúcar, ocorreu um aumento da oxidação dos explantes, em função do aumento da sua concentração no meio nutritivo, chegando ao máximo no tratamento 5 (Brix 6) (Figura 1). $\mathrm{O}$ aumento da oxidação dos explantes, observado de forma crescente a partir do T2, pode ter ocorrido por causa de o melado possuir elevada concentração de compostos fenólicos (Olbrich, 2006; Takara, 2007), os quais, consequentemente, apresentam-se em quantidades mais elevadas em meios nutritivos de melado com maiores valores de Brix.

Apesar de não ter induzido a formação de folhas e de biomassa da matéria fresca, de forma satisfatória, nas plan-

Tabela 1: Análise de variância do número médio de folhas, biomassa da matéria fresca e número médio de raízes, obtidos nos diferentes tratamentos

\begin{tabular}{|c|c|c|c|c|c|c|c|}
\hline \multirow{2}{*}{ F. V. } & \multirow{2}{*}{ G. L. } & \multicolumn{2}{|c|}{$N^{0}$ médio de folhas } & \multicolumn{2}{|c|}{ Biomassa matéria fresca (g) } & \multicolumn{2}{|c|}{$\mathrm{N}^{0}$ médio de raízes } \\
\hline & & Q. M. & $\mathbf{F}$ & Q. M. & $\mathbf{F}$ & Q. M. & $\mathbf{F}$ \\
\hline tratamento & 4 & 17,83 & $93,84 *$ & 0,07 & $28 *$ & 1,56 & $0,89^{\mathrm{NS}}$ \\
\hline resíduo & 20 & 0,19 & & 0,0025 & & 1,76 & \\
\hline total & 24 & & & & & & \\
\hline
\end{tabular}

* Significativo com $5 \%$ de probabilidade.

Ns Não significativo a $5 \%$ de probabilidade. 
Tabela 2: Número médio de folhas, raízes e biomassa da matéria fresca (g) de plantas de bananeira cv. Maçã em função de diferentes formulações de meios nutritivos, no período de 2 meses

\begin{tabular}{|c|c|c|c|}
\hline Tratamentos & $\begin{array}{l}\mathrm{N}^{0} \text { médio } \\
\text { de folhas }\end{array}$ & $\begin{array}{c}\text { Biomassa } \\
\text { da matéria } \\
\text { fresca }(g)\end{array}$ & $\begin{array}{l}\mathrm{N}^{0} \text { médio } \\
\text { de raízes }\end{array}$ \\
\hline MS (controle) & $4,65 \mathrm{a}$ & $0,4 \mathrm{a}$ & $0,93 \mathrm{a}$ \\
\hline Melado (Brix 1,5) & $2,98 \mathrm{~b}$ & $0,17 \mathrm{~b}$ & $0 \mathrm{a}$ \\
\hline Melado (Brix 3,0) & $1,88 \mathrm{c}$ & $0,14 \mathrm{~b}$ & $1,17 \mathrm{a}$ \\
\hline Melado (Brix 4,5) & $0,5 \mathrm{~d}$ & $0,11 \mathrm{~b}$ & $0,15 \mathrm{a}$ \\
\hline Melado (Brix 6,0) & $0 \mathrm{~d}$ & $0,15 \mathrm{~b}$ & $0 \mathrm{a}$ \\
\hline
\end{tabular}

Dados acompanhados de uma mesma letra não diferem estatisticamente pelo Teste de Tukey com $5 \%$ de probabilidade.

tas de bananeira, cv. Maçã, o melado de cana-de-açúcar já foi utilizado com sucesso em experimentos de micropropagação. Santana et al. (2009) utilizaram-no como fonte de carboidrato e vitaminas, para o cultivo in vitro de mandioca, e observaram que o número médio de folhas e de raízes e a biomassa da matéria seca e fresca das plantas não diferiram do controle. Dhamankar (1992) utilizou melado de cana-de-açúcar como meio nutritivo para o cultivo de cana-de-açúcar e conseguiu resultados satisfatórios na indução de calos e brotos.

A diferença observada entre os resultados obtidos neste experimento e aqueles observados pelos autores citados pode ser decorrência da utilização de diferentes espécies vegetais como fonte de explantes, uma vez que espécies vegetais diferentes podem apresentar comportamentos e exigências nutricionais variados, quando cultivadas in vitro (Andrade, 2002).

A variável número médio de raízes não apresentou diferença estatística entre o tratamento controle e os tratamentos utilizando melado de cana-de-açúcar como meio nutritivo. Esse fenômeno pode ser explicado pelo fato de os meios de cultura utilizados, tanto o MS quanto aqueles à base de melado, terem sido acrescidos apenas do regulador vegetal BAP, que é um fitormônio pertencente a classe das citocininas, normalmente utilizadas para a indução da formação de brotos (Taiz \& Zeiger, 2004).

\section{CONCLUSÕES}

O melado de cana-de-açúcar não favorece o desenvolvimento in vitro de plântulas de bananeira.

O melado de cana-de-açúcar pode ser utilizado em substituição ao meio MS para o enraizamento in vitro de bananeira.

\section{AGRADECIMENTOS} ceiro.

\section{REFERÊNCIAS}

Álvares MC \& Caldas LS (2002) Crescimento, produção e variação somaclonal em bananeiras micropropagadas. Pesquisa Agropecuária Brasileira, 37:415- 420.

Andrade SRM. (2002) Princípios da Cultura de Tecidos Vegetais. Planaltina, Embrapa Cerrados. 16p. (Documentos, 58).

Bernardi WF, Rodrigues, BI, Neto, PC, Ando A, Neto AT, Ceravolo LC \& Montes SMNM (2004) Micropropagação de baixo custo em bananeira cv. Maçã em meios com diferentes fontes de carbono e avaliação da performance em campo das mudas produzidas. Revista Brasileira de Fruticultura, 26:503-506.

Buah JN, Tachie-Menson JW, Addae G \& Asarev P (2011) Sugarcane Juice as an Alternative Carbon Source for in vitro Culture of Plantains and Bananas. American Journal of Food Technology, 6:685-694.

Camolesi MR, De Faria RT, Neves CSVJ \& Martins NA (2010) Volume do frasco e consistência do meio de cultura na multiplicação in vitro da bananeira 'Maçã'. Ciência Rural, 40:359-365.

Costa FHS, Pereira MAA, De Oliveira JP \& Pereira JES (2007) Efeito de agentes geleificantes alternativos no meio de cultura no cultivo in vitro de abacaxizeiro e bananeira. Ciência e Agrotecnologia, 31:41-46.

Costa FHS, Pasqual M, Dos Santos AM, De Castro EM \& Scherwinski-Pereira JE (2008) Modificações na anatomia foliar de bananeiras durante o processo de micropropagação. INCI, 33:663-667.

Couceiro MA, Siqueira LD, Pereira WE \& Neves LLM (2001) Crescimento de explantes in vitro e de mudas de bananeira cv. Maçã, submetidas a doses de sacarose nas fases de enraizamento e aclimatação. Revista Ceres, 48:615-627.

Dhamankar VS (1992) Molasses, a source of nutrients for in vitro sugar cane culture. Sugar Cane, 4:14-15.

Diniz JDN, Gonçalves NA \& Minami K (1996a) Variação do pH do meio de cultura in vitro para explantes de bananeira cv. Prata Anã. Revista Ciência Agronômica, 27:87-91.

Diniz JDN, Gonçalves NA \& Minami K (1996b) Crescimento de explantes de bananeira, cv. Prata Anã, in vitro. Revista Ciência Agronômica, 27:92-98.

Faria RT, Dalio RJD, Unemoto LK \& Silva GL (2006) Propagação in vitro de Oncidium baueri Lindl. (Orchidaceae) sem uso de agar. Acta Scientiarum Agronomy, 28:71-74.

Kodym A \& Zapata FJA (2001) Low-cost alternatives for the micropropagation of banana. Plant Cell Tissue and Organ Culture, 66:67-71.

Ledo AS, Lameira AO \& Benbadis A (2002) Explantes de cupuaçuzeiro submetidos a diferentes condições de cultura in vitro. Revista Brasileira de Fruticultura, 24:604-607.

Madail RH, Pio LAS, Pasqual M \& Silva SO (2011) Caracterização morfológica de cultivares de bananeira micropropagadas em estádio juvenil. Ciência Rural, 41:219-222

Murashige T \& Skoog F (1962) A revised medium for rapid growth and bioassays with tobacco tissue cultures. Physiologia Plantarum, 15:473-497.

Olbrich H (2006) The mosasses. Berlin, Biotechnology-Kempe GmbH. 131 p.

Pereira MCT, Nietsche S, França AC, Nunes CF, Lima C, Gonçalves V, Salles BP, Morais DLB \& Kobayashi MK (2005) Aclimatização de mudas micropropagadas de bananeira sob diferentes condições de luminosidade. Revista Brasileira de Fruticultura, 27:238-240. 
Ponce JNP, Castellá MS, Pérez PO (2000) Possibilidades y potencial de la propagación masiva de plantas en Cuba. Biotecnología Vegetal, 1:3-12.

Prakash S, Hoque MI \& Brinks T (2004) Culture media and containers. In: Technical Meeting Of Low Costs Options For Tissue Culture Technology In Developing Countries, 2002, Viena. Proceedings, IAEA: FAO. p. 29-40.

Ramos RS, Motoike SY, Moura EF, Gomes SBS, Rodrigues VF \& Oliveira MAR (2009) Efeito da uréia no alongamento e enraizamento de microplantas de bananeira in vitro. Ciência e Agrotecnologia, 33:1842-1846.

Ribeiro JM \& Teixeira SL (2008a) Esterilização química de meios nutritivos para cultivo in vitro de plantas. Petrolina, Embrapa Semi-Árido 4p. Comunicado Técnico, 136.

Ribeiro JM \& Teixeira SL (2008b) Substituição de nitrato de potássio (PA) por salitre potássico no preparo de meio de cultura de tecidos vegetais esterilizado com hipoclorito de sódio. Ciência e Agrotecnologia, 32:1209-1213.

Ribeiro JM, Canuto KM \& Veschi JLA (2008) Compostos clorados: aspectos gerais e sua utilização como agente sanitizante na agricultura, micropropagação e pecuária. Petrolina, Embrapa Semiárido. 26 p. Documentos, 207.

Ribeiro JM \& Teixeira SL \& Bastos DC (2009) Calogênese em explantes de Pfaffia glomerata (Spreng.) Pedersen cultivados em meio nutritivo esterilizado com hipoclorito de sódio. Revista Ceres, 56:537-541.

Ribeiro JM, Teixeira SL \& Bastos DC (2011) Cultivo in vitro de Sequoia sempervirens L. em meio de nutritivo esterilizado com hipoclorito de sódio. Revista Ciência Florestal, 21:79-84.
Sá MEL \& Braga MF (2002) Avaliação de protocolo para obtenção de mudas micropropagadas de bananeira cv. Prata-anã (subgrupo AAB). Revista Brasileira de Fruticultura, 24:236-239.

Santana MA, Romay G, Matehus J, Vicente-Villardón JL \& Demey JR (2009) A simple and low-cost strategy for micropropagation of cassava (Manihot esculenta Crantz). African Journal of Biotechnology, 8:3789-3897.

Taiz L \& Zeiger E (2004) Fisiologia vegetal. $3^{\text {a }}$ ed. Porto Alegre, Artmed. 719 p.

Takara K, Ushijima K, Wada K, Iwasaki H \& Yamashita M (2007) Phenolic compounds from sugar cane molasses possessing antibacterial activity against cariogenic bacteria. Journal of Oleo Science, 56:611-614.

Teixeira SL, Ribeiro JM \& Teixeira MT (2006) Influence of NaClO on nutrient medium sterilization and on pineapple (Ananas comosus cv Smooth cayenne) behavior. Plant Cell, Tissue and Organ Culture, 86:375-378.

Teixeira SL, Ribeiro JM \& Teixeira MT (2008) Utilização de hipoclorito de sódio na esterilização de meio de cultura para multiplicação in vitro de Eucalyptus pellita. Revista Ciência Florestal, 8:185-191.

Teixeira LAJ (2000). Bananeira (Musa spp). In: Meletti, LMM Propagação de frutíferas tropicais. Guaíba, Agropecuária. p.105124.

Viaganó RC, Bianchi VJ, Rocha PSG, Schuch MW \& Fachinello JC (2007) Enraizamento in vitro do porta-enxerto Prunus cv. Mr. S. 1/8: Concentrações de IBA em meio de cultura acrescido de ágar ou vermiculita. Bioscience Journal, 23:60-65.

White PR (1943) Nutrient deficiency studies and an improved inorganic nutrient medium for cultivation of excised tomato roots. Growth, 7:53-65. 